\title{
Numerical and experimental investigation of shear strength between the steel tube and cement paste in petroleum wells
}

\author{
José F Silva Neto ${ }^{1 *}$, Elisângela P Silva ${ }^{2}$, Kelly C Gomes ${ }^{3}$, Sandro M Torres ${ }^{4}$ and Silvio de Barros ${ }^{5}$
}

\author{
* Correspondence: \\ josefelix@cear.ufpb.br \\ ${ }^{1}$ Department of Renewable Energy \\ Engineering, UFPB, João Pessoa, Brazil \\ Full list of author information is \\ available at the end of the article
}

\begin{abstract}
The push-out test is used to measure the level of adhesion between the steel and cement, a fundamental factor for mechanical and chemical stability in oil wells. In this paper, the numerical simulation of the mechanical behavior of the steel-cement interface was performed. For this purpose, it was used a mathematical model combining the characteristics of non-damaged interface progressing to the complete deterioration with the action of an external shear force. The proposed model was implemented in CAST3M software. To validate the proposed model, push-out tests were performed with three different interface conditions. These tests made possible the observation of the influence of the different conditions used in the experiments and the sensibility of the model variables to these changes.
\end{abstract}

Keywords: Interface; Numerical simulation; Push-out test; Damage; Friction

\section{Background}

The push-out test is the main tool used to evaluate the strength of the structure composing an oil well. This structure is composed of a coated steel pipe by cement. The information to be analyzed after the test, is the maximum force of adhesion which is the maximum load supported by the specimen during testing.

The adhesion results of the superficial interaction at the interface between materials placed in contact with each other. Mathematical models of interface called cohesive zone models simulate the mechanical behavior of these interfaces when subjected to stress, including possible loss of adherence resulting from the action of a load greater than that supported by the interface. In these models, the decohesion between the two bodies joined at the interface is described by a mathematical relationship between the stresses acting on the interface and its opening [1-4].

In this work, the cohesive zone model proposed by Valoroso and Champaney [5] will be applied in the study of the behavior of steel-cement interface, submitted to static loading. The results obtained with the mathematical model are compared to 
experimental results with three different interface conditions. The purpose is to find the best contact condition between steel and cement.

\section{Methods}

Push-out tests were performed to evaluate three different conditions at the interface between the steel and cement. This test consists of extracting the steel pipe of a cylindrical cement block. The extraction is done by pushing only the steel tube causing shear stresses at the contact surface between steel pipe and cement cylinder, as shown in Figure 1. The information to be analyzed after the test is the maximum force of adhesion that is the maximum load supported by the specimen during testing.

For tests were used specimens molded by the following materials: Galvanized steel pipe ABNT 1030, with an outer diameter of $33.70 \mathrm{~mm}$, internal diameter of $28.40 \mathrm{~mm}$ and $200.00 \mathrm{~mm}$ in length; molds of cylindrical specimens of steel with outer diameter of $55.00 \mathrm{~mm}$, inner diameter of $50.00 \mathrm{~mm}$ and $100.00 \mathrm{~mm}$ in length; nylon to fixing base; Cement CP V-ARI; potable water; sodium chloride $(\mathrm{NaCl})$; Kaolin; Silicate alkaline sodium PQ-1.65, with PH 11-13; P220 Sandpaper water; Ethanol.

Three push-out tests were performed, each one with different interface condition, namely: Smooth and dried (later named by $S D$ ), consisting of direct contact between

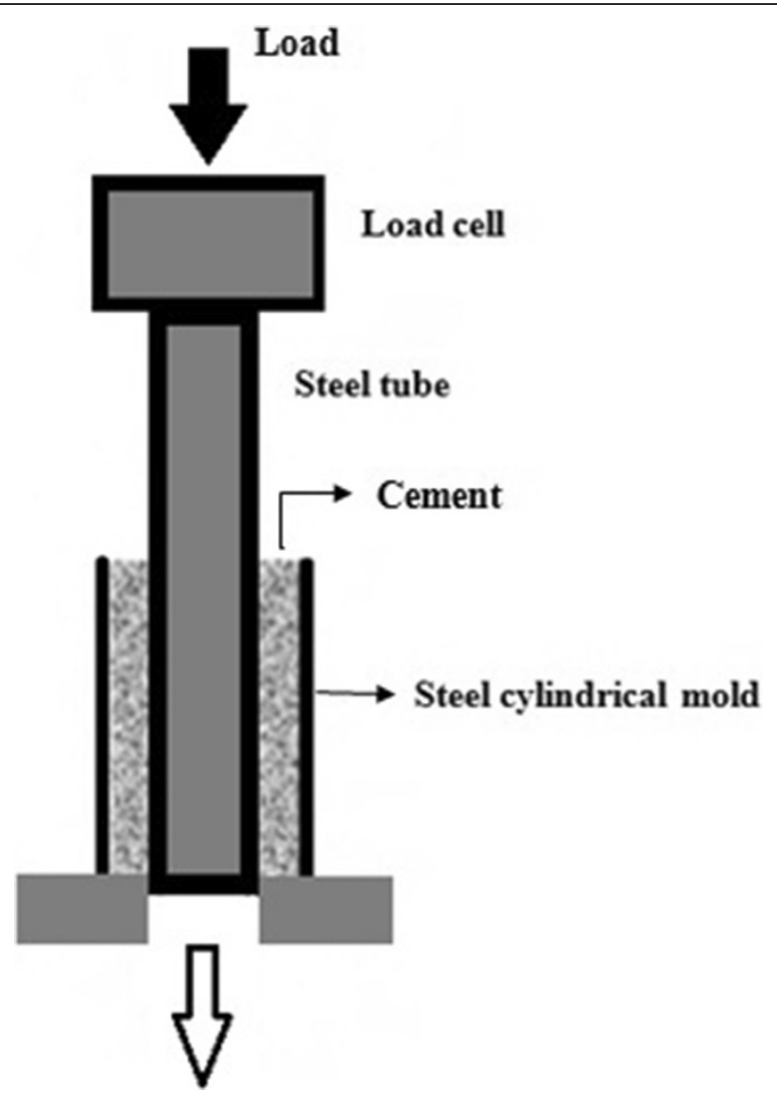

Figure 1 Representation of static push-out test. 
the steel and cement; $N W$ as the interface with presence of $3 \%$ solution of $\mathrm{NaCl}$ in $1 \mathrm{~L}$ of water, and GP corresponding the interface with geopolymer synthesized with kaolin and sodium silicate.

The specimens were prepared as follows: First of all, the galvanized steel tubes were sandpapered removing rust and galvanic coverage, and then cleaned with ethanol. The cement paste was prepared with cement and water, following the water/cement ratio of 0.44, which is the standard reason used in cementing of petroleum wells, according to Economides et al. [6].

For $S D$ condition, the steel tube was initially washed with water and dried with ethanol. In this condition, the steel tube has not undergone any chemical treatment. The specimen was molded by placing the steel tube in the mold and injecting the cement paste.

The NW condition consisted perform a chemical treatment on the surface of the steel tube before placing it in the mold. This chemical treatment refers to spray the tube, a solution of $3 \% \mathrm{NaCl}$ in $1 \mathrm{~L}$ of water, approximately corresponding to the salt content in seawater and used in drilling fluids. After chemical treatment, the tube was placed into the mold and the cement is injected in the same manner as in the $S D$ condition.

To GP condition, before placing the tube into the mold and injecting cement, the geopolymer coating was applied to the base of kaolin and sodium silicate on the surface. To the preparation of geopolymer, it was initially performed the kaolin calcining, heated to $700^{\circ} \mathrm{C}$ for $2 \mathrm{~h}$, such as the kaolin reaches to the metakaolin condition and becomes more reactive. After manual mixing of the geopolymer precursors, the tube was coated with a layer of cement from the geopolymer synthesized with $2 \mathrm{~mm}$ and the same was brought to the drying oven to cure and remained at $55^{\circ} \mathrm{C}$ for 24 hours, conditions which provide good mechanical properties to the geopolymer [7]. Finally, after the curing of the geopolymer, the tube coated with this material was placed into the mold and the cement was injected, concluding the molding of the specimen.

After molding, all samples were maintained at a temperature of $60^{\circ} \mathrm{C}$ for a period of three days. The specimens were transported to the testing machine, which were also tested at $60^{\circ} \mathrm{C}$. The testing machine used was Shimadzu Servopulser with $50 \mathrm{kN}$ load cell and has an integrated oven, allowing the tests above ambient temperature. Figure 2 shows the specimen during the test.

The cohesive model proposed by Valoroso and Champaney [5] is used in this study. The push-out static test described above was simulated in the finite element software Cast3M [8], developed by the Commissariat à l'Energie Atomique (CEA) in France.

Three different meshes were created to represent the specimen: A two-dimensional representing the steel pipe with 600 quadrangular elements with 4 knots, a twodimensional representing the cementitious coating, with 1000 quadrangular elements with 4 knots, and a one-dimensional representing the interface between the steel and cement, with 100 linear elements with 2 knots.

The parameters used in the model for simulating the push-out test were grouped in Table 1. Each parameter combination is equivalent to one of the conditions tested. All values, except the friction coefficient $\mu$, were chosen based on the experimental 


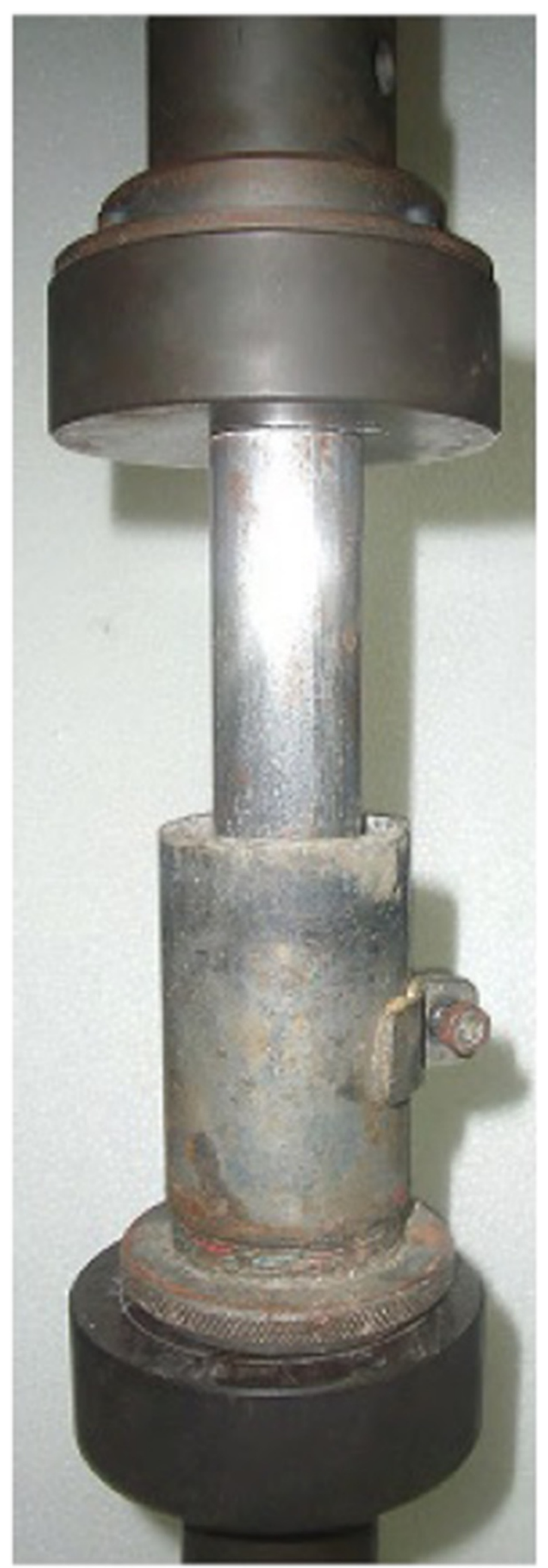

Figure 2 Specimen during the static push-out test. 
Table 1 Parameters of the interface model

\begin{tabular}{lccc}
\hline Parameter & \multicolumn{2}{c}{ Simulation } \\
\cline { 2 - 4 } & SD & NW & GP \\
\hline Normal stiffness of the interface $\left(\mathrm{k}_{\mathrm{n}}\right)\left[\mathrm{N} / \mathrm{mm}^{3}\right]$ & 3.800 & 4.000 & 2.000 \\
Tangential stiffness of the interface $\left(\mathrm{k}_{\mathrm{s}}\right)\left[\mathrm{N} / \mathrm{mm}^{3}\right]$ & 3.800 & 4.000 & 2.000 \\
Activation energy in mode II $\left(\mathrm{G}_{\mathrm{OII}}\right)[\mathrm{N} / \mathrm{mm}]$ & 0.140 & 0.195 & 0.025 \\
Energy critical mode II $\left(\mathrm{G}_{\mathrm{cII}}\right)[\mathrm{N} / \mathrm{mm}]$ & 0.480 & 0.950 & 0.100 \\
Exponent of the power of steering of the damage $(\mathrm{N})$ & 2.000 & 2.500 & 1.800 \\
Coefficient of friction $(\mu)$ & 0.470 & 0.470 & 0.470 \\
Pressure at the interface $(P)[\mathrm{MPa}]$ & 4.000 & 4.500 & 1.950 \\
\hline
\end{tabular}

results. The value of $\mu$ obeys the results obtained by Baltay and Gjelsvik [9] and Wang et al [10].

\section{Results and discussion}

The model was implemented in the finite element software (Cast3M). Figures 3,4 and 5 show the force-displacement curves obtained and compared with the experimental results.

It was noticed that the curves of the three samples tested have a similar behavior, according the result of a typical push-out test, although the maximum force adhesion and the friction force are not the same.

In all three cases, the curve initially presented a linear behavior, representing a perfect adhesion between the steel and cement. This linear behavior continued until the maximum force of adhesion was reached. After reaching the maximum adhesion force, the interface was damaged progressively until full rupture. This phenomenon is identified by gradual decrease of the value of the adhesion force to a constant value corresponding to the frictional force.

The $N W$ interface condition showed higher adhesion tension compared to other samples and this can be justified because the cement hydration is accelerate by the ionic species present on the salt increasing their resistance. It is also possible that the chlorine ions act catalytically in the process of corrosion of metal piping and creating a more roughened surface, thus improving the adhesion.

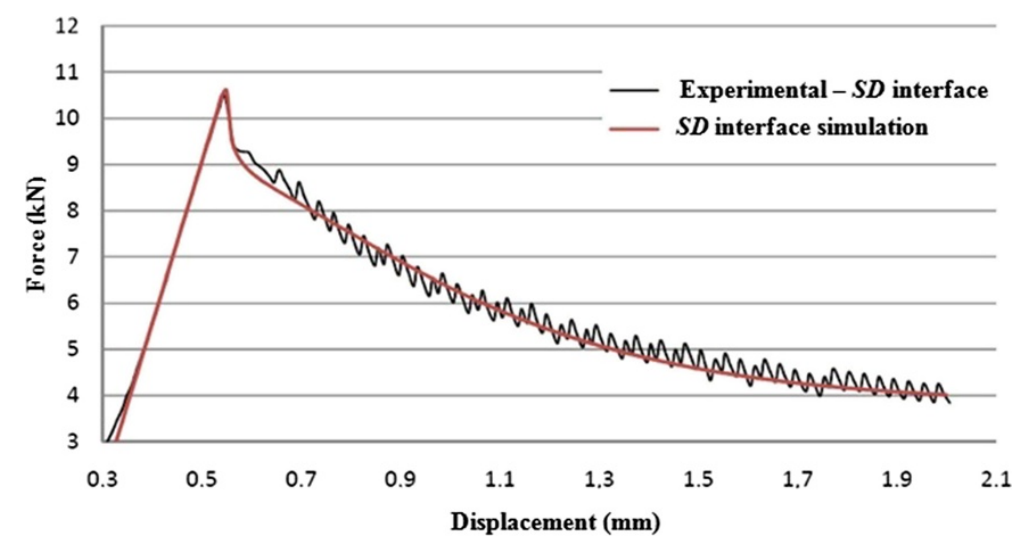

Figure 3 Comparison between the experimental and the numerical result in SD condition. 


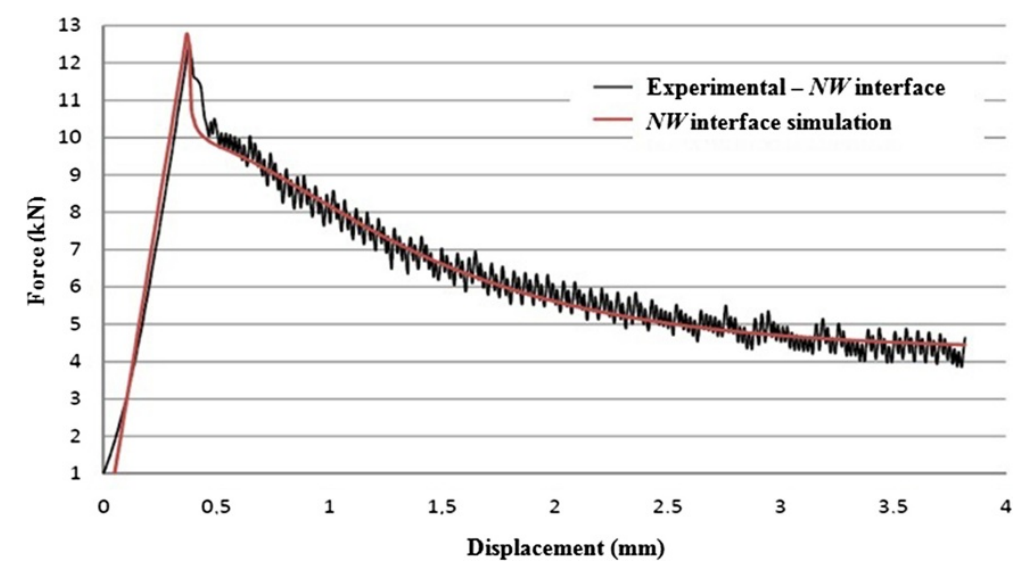

Figure 4 Comparison between the experimental and the numerical result in NW condition.

The GP interface condition showed the lowest adhesion tension among tests. This may have occurred because of geopolymers mechanical resistance decreases with increasing water content in its composition, caused by geopolymers contact with the water present in the cement.

\section{Conclusion}

Among the interface conditions tested, the condition $N W$ showed the better results. This can be explained mainly by the positive influence of chloride ions on the cement hydration ions and by the surface corrosion of the steel tube, improving the surface's wettability.

The numerical results reproduced exactly what was seen experimentally, although the first two conditions of simulated interface $(S D$ and $N W$ ) were not able to reproduce, in the simulation, the oscillating behavior of the experimental curves. The proposed interface model reproduces the damage evolution at the interface and the combination with formulation for friction provides a coherent response with what was observed in the experiments.

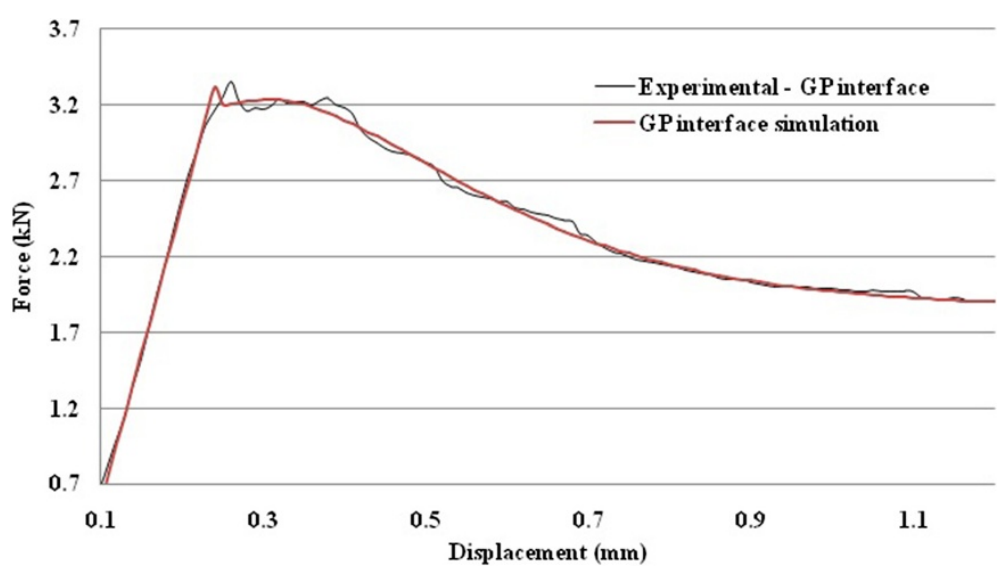

Figure 5 Comparison between the experimental and the numerical result in GP condition. 


\begin{abstract}
Abbreviations
ABNT: Brazilian Association of Standard Techniques; CEA: Commissariat à I'Energie Atomique; GP: Interface condition with geopolymer; LABEME: Testing Laboratory of Materials and Structures; LSR: Laboratory of Rapid Solidification; NBR: Brazilian standard; NW: Interface condition with sodium chloride and water; SD: Smooth and dried interface condition; UFPB: Federal University of Paraíba.
\end{abstract}

\title{
Competing interests
}

The authors declare that they have no competing interests.

\section{Authors' contributions}

JFSN and SdB carried out the numerical simulation and compared with the experimental data. EPS and SMT carried out the experiments. KCG helped to draft the manuscript and revised it content. All authors read and approved the final manuscript.

\section{Acknowledgments}

The authors acknowledge the financial support of the Brazilian Agencies FAPERJ, CNPq and CAPES. The authors are also grateful to "Caulisa Indústria de Caulim S/A" for providing the raw material for the geopolymer manufacturing.

\section{Author details}

${ }^{1}$ Department of Renewable Energy Engineering, UFPB, João Pessoa, Brazil. ${ }^{2}$ Newly Doctor UFPB, João Pessoa, Brazil. ${ }^{3}$ Department of Soils and Rural Engineering, UFPB, Areia, Brazil. ${ }^{4}$ Department of Materials Engineering, UFPB, João Pessoa, Brazil. ${ }^{5}$ Department of Mechanical Engineering, CEFET/RJ, Rio de Janeiro, Brazil.

Received: 2 September 2013 Accepted: 27 December 2013

Published: 3 February 2014

\section{References}

1. Alfano G, Sacco E (2006) Combining interface damage and friction in a cohesive-zone model. Int J Num Meth Eng 68:542-582, doi:10.1002/nme.1728

2. Valoroso N, Champaney L (2006) A damage-mechanics-based approach for modeling decohesion in adhesively bonded assemblies. Eng Fract Mech 18:2774-2801, doi:10.1016/j.engfracmech.2006.04.029

3. De Barros S, Champaney L, Valoroso N (2012) Numerical simulations of crack propagation tests in adhesive bonded joints. Latin Am J Solids Struct 9:339-351

4. Allix O, Ladevèze P (1992) Interlaminar interface modelling for the prediction of delamination. Compos Struct 22:235-242, doi:10.1016/0263-8223(92)90060-P

5. Valoroso N, Champaney L (2006) A damage-friction formulation for the de-cohesion analysis of adhesive joints. Proc Fifth Int Conf Eng Comp Technol, doi:10.4203/ccp.103

6. Economides MJ, Watters LT, Dunn-Norman S (1997) Petroleum well construction. John Wiley and Sons, Duncan, Oklahoma

7. De Barros S, Gomes KC, De Souza JR, Barbosa NP, Torres SM (2010) Geopolymeric adhesives for aluminium joints. Mater Sci Forum 643:143-146, doi:10.4028/www.scientific.net/MSF.643.143

8. (2003) CASTEM, CEA. http://www-cast3m.cea.fr. CAST3M - User Manual

9. Baltay P, Gjelsvik A (1990) Coefficient of friction for steel on concrete at high normal stress. J Mat Civil Eng 2:46-49, doi:10.1061/(ASCE)0899-1561(1990)2:1(46)

10. Wang $\mathrm{H}$, Li H, Yan F (2005) Synthesis and tribological behavior of metakaolinite-based geopolymer composites. Mat Letters 59:3976-3981, doi:10.1016/j.matlet.2004.08.049

doi:10.1186/2196-4351-2-4

Cite this article as: Silva Neto et al:: Numerical and experimental investigation of shear strength between the steel tube and cement paste in petroleum wells. Applied Adhesion Science 2014 2:4.

\section{Submit your manuscript to a SpringerOpen ${ }^{\circ}$ journal and benefit from:}

- Convenient online submission

- Rigorous peer review

- Immediate publication on acceptance

- Open access: articles freely available online

- High visibility within the field

Retaining the copyright to your article

Submit your next manuscript at $\gg$ springeropen.com 